\title{
Artificial light at night alters life history in a nocturnal orb- web spider
}

\author{
Nikolas J Willmott ${ }^{\text {Corresp., }}{ }^{1}$ ， Jessica Henneken ${ }^{1}$, Caitlin J Selleck ${ }^{1}$ ， Therésa M Jones ${ }^{1}$ \\ ${ }^{1}$ School of BioSciences, University of Melbourne, Melbourne, Victoria, Australia \\ Corresponding Author: Nikolas J Willmott \\ Email address: nwillmott@student.unimelb.edu.au
}

The prevalence of artificial light at night (ALAN) is increasing rapidly around the world. The potential physiological costs of this night lighting are often evident in life history shifts. We investigated the effects of chronic night-time exposure to ecologically relevant levels of LED lighting on the life history traits of the nocturnal Australian garden orb-web spider (Eriophora biapicata). We reared spiders under a 12-hour day and either a 12-hour natural darkness ( $\sim 0$ lux) or a 12-hour dim light ( 20 lux) night and assessed juvenile development, growth and mortality, and adult reproductive success and survival. We found that exposure to ALAN accelerated juvenile development, resulting in spiders progressing through fewer moults, and maturing earlier and at a smaller size. There was a significant increase in daily juvenile mortality for spiders reared under 20 lux, but the earlier maturation resulted in a comparable number of 0 lux and 20 lux spiders reaching maturity. Exposure to ALAN also considerably reduced the number of eggs produced by females, and this was largely associated with ALAN-induced reductions in body size. Despite previous observations of increased fitness for some orb-weavers in urban areas and near night lighting, it appears that exposure to artificial night lighting may lead to considerable developmental costs. Future research will need to consider the detrimental effects of ALAN combined with foraging benefits when studying nocturnal insectivores that forage around artificial lights. 


\section{Artificial light at night alters life history in a nocturnal orb- web spider}

3

4

Nikolas J. Willmott, Jessica Henneken, Caitlin J. Selleck, Therésa M. Jones

5

School of Biosciences, The University of Melbourne, Victoria 3010, Australia

6

7

8

9 Author for correspondence

10 Nikolas J. Willmott

11 nwillmott@student.unimelb.edu.au

12 School of BioSciences, The University of Melbourne, Victoria 3010, Australia. 


\section{ABSTRACT}

14 The prevalence of artificial light at night (ALAN) is increasing rapidly around the world. The

15 potential physiological costs of this night lighting are often evident in life history shifts. We

16 investigated the effects of chronic night-time exposure to ecologically relevant levels of LED

17 lighting on the life history traits of the nocturnal Australian garden orb-web spider (Eriophora

18 biapicata). We reared spiders under a 12-hour day and either a 12-hour natural darkness ( $\sim 0$ lux $)$

19 or a 12-hour dim light ( 20 lux) night and assessed juvenile development, growth and mortality,

20 and adult reproductive success and survival. We found that exposure to ALAN accelerated

21 juvenile development, resulting in spiders progressing through fewer moults, and maturing

22 earlier and at a smaller size. There was a significant increase in daily juvenile mortality for

23 spiders reared under 20 lux, but the earlier maturation resulted in a comparable number of 0 lux

24 and 20 lux spiders reaching maturity. Exposure to ALAN also considerably reduced the number

25 of eggs produced by females, and this was largely associated with ALAN-induced reductions in

26 body size. Despite previous observations of increased fitness for some orb-weavers in urban

27 areas and near night lighting, it appears that exposure to artificial night lighting may lead to

28 considerable developmental costs. Future research will need to consider the detrimental effects

29 of ALAN combined with foraging benefits when studying nocturnal insectivores that forage

30 around artificial lights. 


\section{INTRODUCTION}

32 The spread of artificial light at night (ALAN) is increasing rapidly around the globe and its

33 presence has been linked to shifts in physiological and behavioural traits in animals (Gaston et

34 al., 2013; Longcore \& Rich, 2004). Exposure to ALAN is directly linked to changes in key life

35 history traits, including variation in patterns of juvenile growth (Brüning et al., 2011), reductions

36 in immune function (Bedrosian et al., 2011; Durrant et al., 2015), survival (Shah et al., 2011) and

37 fecundity (McLay et al., 2017), as well as shifts in reproductive behaviours (Firebaugh \&

38 Haynes, 2016; McLay et al., 2017; van Geffen et al., 2014, 2015). Indirectly, where exposure to

39 night lighting stimulates earlier maturation and smaller adult size, there may be reproductive

40 costs due to poorer male performance (Elgar \& Jones, 2008; van Geffen et al., 2014) and reduced

41 female fecundity (Honěk \& Honek, 1993; van Geffen et al., 2014). Adults that emerge earlier

42 may benefit if this extends their potential breeding period and thus increases offspring

43 production (Lowe et al., 2014; Schneider \& Elgar, 2002). However, each sex may respond

44 differently to the presence of ALAN, and maturation time for males and females could

45 desynchronise, potentially resulting in catastrophic reductions in reproductive success (Dominoni

46 et al., 2013; van Geffen et al., 2014).

47 A potential underlying mechanism for these life history shifts is that the presence of ALAN may

48 simulate a longer day and/or mask daily and seasonal patterns of light. Changes in natural

49 lighting drive a multitude of daily and seasonal biological rhythms, including reproduction

50 (Nelson et al., 2010; Tauber et al., 1986), and thus ALAN may have serious consequences for

51 juvenile development and reproductive maturation (McLay et al., 2017; Shah et al., 2011; van

52 Geffen et al., 2014). For species that exhibit seasonal diapause or overwintering (Schaefer, 1987;

53 Shah et al., 2011; van Geffen et al., 2014), disruption by ALAN (simulating long-day 
54 photoperiods that naturally suppress diapause; Nylin \& Gotthard, 1998) can result in earlier

55 maturation (van Geffen et al., 2014) and may increase mortality (Shah et al., 2011). However,

56 there is variation in these patterns across taxa, as development time may also be shortened in

57 vertebrate species that do not exhibit diapause (Brüning et al., 2011; Dominoni et al., 2013). This

58 suggests the effects of ALAN on life history depend on species-specific physiological and life

59 history traits.

60 The detrimental effects of ALAN are potentially exacerbated if animals are attracted to artificial

61 lights. Many species exhibit positive phototaxis (for example, attraction towards natural

62 moonlight or light reflecting off water bodies), which is an adaptive trait facilitating behaviours

63 such as navigation (Minnaar et al., 2015; van Langevelde et al., 2011) or foraging site choice

64 (Heiling, 1999; Rydell, 1992). For these species, ALAN may act as an ecological trap (sensu,

65 Hale \& Swearer, 2016) resulting in individuals settling in poor quality habitats (Gerhard

66 Eisenbeis \& Hänel, 2009; Gaston et al., 2012; Longcore \& Rich, 2004). Conversely, nocturnal

67 insectivores may gain direct benefits if they forage around artificial lights because increased prey

68 densities around these lights facilitate increased foraging success (Adams, 2000; Heiling \&

69 Herberstein, 1999; Lacoeuilhe et al., 2014). However, while research demonstrates that

70 insectivores (in particular) may gain foraging benefits from the presence of ALAN, the potential

71 physiological costs of ALAN are largely unstudied.

72 Spiders are an ideal taxon for investigating the relative ecological costs and benefits of the

73 presence of ALAN. Simulated long-day photoperiods may induce shifts in a spider's maturation

74 period, reducing the number of juvenile instars (Miyashita \& Department, 1987; Nylin \&

75 Gotthard, 1998; Schaefer, 1987); a pattern that likely varies with species and life history stage

76 (Schaefer, 1987). Additionally, some species are urban exploiters, meaning they perform well in 
77 urban habitats (Bolger et al., 2008; Lowe et al., 2014; Shochat et al., 2004). However, it is not

78 always clear which urbanisation factors (e.g. light, noise, temperature and habitat fragmentation)

79 or which species traits drive this urban exploitation (Trubl et al., 2012). Broadly, urbanisation

80 drives shifts in temperature, prey availability, and other correlated factors that potentially alter

81 spider development, including time to maturation and total growth (Bonaric, 1987; Lowe et al.,

82 2014; Mayntz et al., 2003; Vollrath, 1987). The specific impact of artificial light is often omitted

83 when investigating the effects of urbanisation on spiders (Dahirel et al., 2017; Lowe et al., 2014).

84 This is a surprising oversight, as many orb-weavers preferentially construct their webs in open

85 spaces and so are likely to be attracted to artificial lighting during foraging site choice (C. L.

86 Craig \& Bernard, 1990; Heiling, 1999), and importantly, artificial lights aggregate their

87 nocturnal insect prey (Heiling \& Herberstein, 1999; Kreiter \& Wise, 2001; Longcore \& Rich,

88 2004). Additionally, orb-web spiders are particularly immobile predators once they have selected

89 a foraging site, so compared to more mobile insectivores such as bats and geckos, they are likely

90 to be exposed to ALAN to a much greater extent.

91 We investigated the effects of lifetime exposure to ALAN on key life history traits (juvenile

92 development rate, total growth and survival, as well as adult reproductive output and survival) in

93 the Australian garden orb-web spider (Eriophora biapicata). These large nocturnal spiders (body

94 length up to $22 \mathrm{~mm}$ in females and $18 \mathrm{~mm}$ in males) are prevalent in urban and suburban habitats

95 and often build their webs near or on artificial lights. Additionally, they forage primarily on

96 species of Lepidoptera, Coleoptera, and Diptera (Herberstein \& Elgar, 1994), many of which are

97 highly attracted to lights (Gerhard Eisenbeis \& Hänel, 2009). In good quality foraging sites such

98 as around street lights, which attract abundant nocturnal invertebrate prey, E. biapicata juveniles

99 demonstrate high foraging site persistence (NJW, under review). Hence, they are an ideal species 
100 for investigating the life history consequences of ALAN exposure, as they are likely to be

101 chronically exposed to the effects of artificial light at night in urban areas.

\section{MATERIALS \& METHODS}

\section{Collection and Housing}

104 Experimental spiders were obtained from eggsacs laid in the laboratory by 18 wild-caught

105 Eriophora biapicata females, collected from sites ranging in light intensity from $<0.1$ lux to 40

106 lux (Skye Instruments Lux Meter) in an urban park in Melbourne, Victoria (37.7911 S, 144.9515

107 E) in February 2016. Spiderlings from these 18 families were reared from hatching at $22^{\circ} \mathrm{C}$ under

108 a 12-hour day (2000 lux; 12V cool white LED strip lighting; Figure S1) and a 12-hour night that

109 was either darkness ( 0 lux treatment; $\mathrm{n}=215 ; 0-0.06$ lux $)$ or dim light at night (20 lux

110 treatment; $\mathrm{n}=235 ; 20-24.6$ lux; 12V cool white LED strip lighting). We selected 20 lux as it

111 sits in the middle of the range of light intensities experienced by spiders in our collection site,

112 and is comparable to other laboratory studies mimicking the effects of streetlighting (e.g.

113 Durrant, et al., 2018; McLay et al., 2017). Offspring from each family contributed equally to

114 each of the two light treatments. At $14.95 \pm 1.47$ (mean \pm SE) days after emergence from the egg

115 sac, juvenile spiders were transferred to inverted, transparent plastic cups and maintained until

116 death under standard laboratory conditions (Henneken et al., 2015). To maintain humidity, cups

117 were lightly misted with water every two days. Young juveniles (hatching until $7^{\text {th }}$ instar) were

118 provided with three to five Drosophila melanogaster per week; older juveniles ( $7^{\text {th }}$ instar to

119 penultimate instar) were fed three to five house flies (Musca domestica) per week; and, adults

120 were fed one juvenile cricket (Acheta domesticus) equal to their body size twice a week. All

121 spiders were provided with equal food appropriate to their size and life stage regardless of 
122 treatment group. The amount of food provided to juveniles was based on observations of wild

123 Eriophora. We did not provide ad libitum food during development, which would have been

124 unrealistic and may have masked the effects of ALAN. Spiders were handfed where possible to

125 minimise the effects of lights on prey capture rates. Prey were rarely left completely uneaten

126 regardless of treatment group but adult spiders often discarded food suggesting that they were

127 likely provided ad libitum food.

128 Maturation Time, Survival, and Body Size

129 Spiders were checked every two to three days and any moults or deaths were noted, to assess the 130 effects of the presence of ALAN on development rates and survivorship. The date of death after

131 maturation was taken as a measure of adult lifespan. The age (in days) at which a spider

132 completed its final moult was defined as its age at maturation. Once spiders reached maturity, we

133 measured their body mass $(\mathrm{mg})$ and the length of the tibia $(\mathrm{mm})$ on the front left leg, and used

134 these to determine total life-time growth.

135 Reproductive Success

136 We assessed whether exposure to ALAN during development affected reproductive success by

137 providing spiders with mating opportunities within their own light treatment groups and

138 measuring the number of offspring produced. Mating pairs were age-matched to ensure

139 senescence (days since maturation) differed as little as possible between treatment groups (mean

$140 \pm$ SEM senescence at mating: 0 lux males $=20.32 \pm 2.36$; females $=8.14 \pm 0.81 ; 20$ lux males $=$

$14118.96 \pm 2.56$; females $=10.40 \pm 2.17$ ). Prior to each mating trial, we allowed the female to build

142 a web in a rectangular Perspex frame $(58 \mathrm{~cm} \times 58 \mathrm{~cm} \times 15 \mathrm{~cm})$ after 'sunset' in the laboratory.

143 Following web construction, we placed the male in the bottom corner of the frame furthest from 
144 the hub of the female's web to allow mating. Following mating, both males and females were

145 returned to their normal housing conditions. If a female failed to mate with a male, she was

146 paired with consecutive different males until she mated. For each mated female, we recorded the

147 time between mating and production of the first eggsac, the total number of eggsacs laid, the

148 number of spiderlings that emerged, and the average mass of individual spiderlings in the first

149 eggsac produced by each female; spiderling mass in subsequent eggsacs were not measured due

150 to time constraints. To measure reproductive costs of ALAN due to physiological disruption,

151 independent of reproductive costs due to shifts in body size, we calculated the number of eggs

152 produced per mg of female body mass for each mated female.

\section{Statistical Analysis}

154 Statistical analyses were carried out using R version 3.4.2 (R Core Team, 2017). We used linear

155 mixed models to determine the effects of light treatment (fixed factor), sex (fixed factor) and

156 family (random factor) on age at maturation, length of the intermoult period, and the number of

157 recorded moults. We used a generalised linear mixed model (with an assumed logit link) to

158 compare the proportion of juveniles in each treatment group surviving to maturity, with family as

159 a random factor. We used linear mixed models to determine the effects of light treatment (fixed

160 factor), sex (fixed factor) and family (random factor) on body mass, and tibia length in adults. In

161 the case of a significant treatment $\times$ sex interaction, we used post-hoc comparisons with a

162 Bonferroni correction. Due to the strong correlation between treatment group and age at

163 maturation, relationships between age at maturation and body mass, tibia length, or number of

164 juvenile moults were analysed separately for each treatment group. The marginal $\left(\mathrm{R}_{\mathrm{m}}^{2}\right)$ and

165 conditional $\left(\mathrm{R}_{\mathrm{c}}^{2}\right) \mathrm{R}$-squared values are presented for these analyses. Survival curves (for entire

166 lifespan and separately for adult longevity only) for each treatment group were built using a 
167 Kaplan-Meier survival analysis (lifespan or adult longevity as response, light treatment as fixed

168 factor, family as random factor; sex was a fixed factor for the analysis of adult longevity).

169 Curves were compared using a log-rank test (survival package in R; Therneau, 2015). Linear

170 mixed models were used to test the effects of light treatment (fixed factor) and family (random

171 factor) on the number of eggsacs produced, the number of spiderlings per eggsac, the time to the

172 first eggsac, and the mass of spiderlings in the first eggsac.

\section{RESULTS}

174 Maturation Time and Survival

175 The probability that a juvenile reached maturity was comparable for the two light treatments (72 176 of 2150 lux spiderlings; 64 of 235 LaN spiderlings; GLMM: $\chi^{2}=2.54$, df $=1, P=0.11$ ).

177 However, 20 lux spiders matured significantly earlier (Table 1a) and required fewer moults to

178 reach maturity (Table 1b) compared with 0 lux spiders, for both males and females. The

179 intermoult interval (days) was comparable for $20 \operatorname{lux}$ and 0 lux spiders (Table 1c). There was a

180 positive relationship between time to maturation and the recorded number of moults $\left(\mathrm{F}_{(1,131)}=\right.$

181 109.1, $P<0.0001$; Figure 1). Overall, the total number of days survived (from emergence from

182 the egg to death) by 20 lux spiders was fewer than 0 lux spiders (log-rank test: $\chi^{2}=10.90$, df $=1$,

$183 P<0.001$; Figure 2) but adult survival was comparable for the two light treatments $\left(\chi^{2}=0.001\right.$,

$184 \mathrm{df}=1, P=0.97)$. Regardless of lighting treatment, males matured earlier than females (Table

185 1a) and required fewer moults to reach maturity (Table 1b). The intermoult interval (days) was

186 shorter for females compared to males (Table 1c) and adult females lived longer than males $\left(\chi^{2}=\right.$

$18741.85, \mathrm{df}=1, P<0.0001$; Figure 3).

188 Body Size 
189 There was a significant interaction between light treatment and sex in their effect on body mass

190 at maturation (Table 1d). Post-hoc analyses revealed that female body mass was significantly

191 greater than male body mass in the 0 lux group (estimate $\pm \mathrm{SE}: 169.88 \pm 19.05 ; \mathrm{t}_{130.6}=8.92, \mathrm{P}<$

1920.0001 ), but not in the 20 lux treatment group (estimate $\pm \mathrm{SE}: 36.32 \pm 19.98 ; \mathrm{t}_{124.3}=1.82, \mathrm{P}=$

193 0.29).Additionally, 20 lux spiders were significantly smaller than 0 lux spiders, with a bigger

194 effect in females (males: estimate $\pm \mathrm{SE}: 158.40 \pm 18.14 ; \mathrm{t}_{131.4}=8.73, \mathrm{P}<0.0001$; females:

195 estimate \pm SE: $\left.291.97 \pm 20.70 ; \mathrm{t}_{124.9}=14.11, \mathrm{P}<0.0001\right)$. There was also a significant treatment-

196 sex interaction for tibia length (Table 1e). Post-hoc analyses demonstrated that male tibia length

197 was greater than female tibia length for 20 lux spiders (estimate $\pm \mathrm{SE}: 0.66 \pm 0.17 ; \mathrm{t}_{124.7}=3.91, \mathrm{P}$

$198<0.001$ ) but the sexes were comparable in 0 lux spiders (estimate $\pm \mathrm{SE}: 0.18 \pm 10.16 ; \mathrm{t}_{130.2}=$

$1991.10, \mathrm{P}=1.00)$. Tibia length was significantly greater in 0 lux compared to 20 lux spiders in both 200 males (estimate $\left.\pm \mathrm{SE}: 1.51 \pm 0.15 ; \mathrm{t}_{131.2}=9.79, \mathrm{P}<0.0001\right)$ and females (estimate $\pm \mathrm{SE}: 2.00 \pm$

$\left.2010.18 ; \mathrm{t}_{125.4}=11.37, \mathrm{P}<0.0001\right)$. There was a positive relationship between time to maturation 202 and adult body mass $\left(\mathrm{F}_{(1,131)}=262.35, P<0.0001\right.$; Figure 4) and adult tibial length $\left(\mathrm{F}_{(1,131)}=\right.$ $20340.55, P<0.0001$; Figure 5).

204 Reproductive Success

205 There was no effect of light treatment on the likelihood of a given pair mating $\left(\mathrm{F}_{(1,79)}=1.34, \mathrm{P}=\right.$

206 0.25). The number of eggsacs laid per female was comparable across light treatments (Table 2a),

207 but 20 lux females produced fewer spiderlings overall (Table 2b). On average, 20 lux females

208 produced $63.96 \%$ fewer spiderlings per eggsac (main effect: $\chi^{2}=218.35, d f=1, P<0.0001$;

209 Table 2c). The number of spiderlings per eggsac declined with eggsac number (main effect: $\chi^{2}=$

$21030.07, d f=1, P<0.0001$ ), doing so faster in 0 lux females (interaction: $\chi^{2}=8.42, d f=1, P<$

2110.004 ; Figure 6). The egg to mass ratio (the ratio of the number of eggs per eggsac to female 
212 body mass at maturity) was not significantly different between treatment groups ( 0 lux $=2.11 \pm$

$2130.12 ; \operatorname{LaN}=1.84 \pm 0.16$ eggs per $\mathrm{mg}$ of female; $\left.\mathrm{t}_{45}=1.33, P=0.19\right)$. The time between mating

214 and laying the first eggsac was comparable between treatment groups (mean \pm SEM days: 0 lux

$\left.215=28.54 \pm 2.54 ; \operatorname{LaN}=22.92 \pm 2.15 ; \mathrm{F}_{(1,49)}=2.83, P=0.1\right)$. There was no significant effect of

216 light treatment on the mass of individual spiderlings in the first eggsac (Table 2d).

\section{DISCUSSION}

218 Our study demonstrated dramatic shifts in key life history traits of Eriophora biapicata resulting

219 from chronic exposure to artificial light at night (ALAN). Exposure to ALAN reduced the

220 number of juvenile instars, which resulted in earlier maturation at a smaller body size and

221 ultimately led to a significant reduction in reproductive output. Mortality rates were higher in

222 spiders exposed to ALAN, although earlier maturation meant there was no significant difference

223 between treatment groups in the proportion that reached maturity. Here, we discuss the

224 consequences of these life history shifts in the context of increased foraging success for spiders

225 that build their webs near artificial lights, as we predict this may counter the physiological costs

226 observed.

227 Effects of ALAN on Spider Life History Traits

228 Seasonal shifts in temperature and daily photoperiod regulate patterns of growth and

229 development in the majority of animals, through underling effects on circadian and circannual

230 rhythms (Adkisson, 1966; Gaston et al., 2013; Fonken \& Nelson, 2014; Navara \& Nelson, 2007).

231 Spiders exposed to ALAN, which may emulate the longer photoperiod normally associated with

232 spring and summer, progressed through fewer juvenile moults and matured earlier. This is

233 consistent with similar observations of extended photoperiods reducing instar number and 
234 stimulating earlier maturation in the house spider Achaearanea tepidariorum Koch 1841

235 (Miyashita, 1987). Similarly, ALAN exposure shortened seasonal diapause and caused earlier

236 maturation in other arthropod species (Shah et al., 2011; van Geffen et al., 2014), and

237 overwintering as early instar juveniles has been documented for several spider species (Schaefer,

238 1987). One possible explanation is that spiders exposed to ALAN may skip several winter

239 moults as the nocturnal photic cues they experience mimic spring and summer photoperiods. In

240 our study, we did not observe an overwintering period during which spiders did not moult for

241 either treatment group. Variation in the number of moults required to reach maturity in spiders

242 has been attributed to the photoperiod experienced (Miyashita, 1987). Spiders such as Eriophora

243 may exhibit this plasticity if the ultimate moult is related to when their sexual organs are

244 sufficiently developed, rather than moult number. Hence, perception of an extended photoperiod

245 (indicating the longer days typical of the reproductive season) would stimulate faster sexual

246 development and earlier maturation, potentially driven by a fundamental shift in the biological

247 clocks of the spiders. It is possible that moulting occurs during natural overwintering, but these

248 moults are likely associated with only small increases in body mass. This shift in the rate of

249 development may be related to a documented physiological effect of ALAN: its suppression of

250 the nocturnal synthesis of melatonin (Jones et al., 2015). Melatonin is a highly evolutionarily

251 conserved molecule (Vivien-Roels \& Pévet, 1993) that is linked to circadian and circannual

252 rhythms and appears to have a regulatory function for moulting in arthropods (Girish et al.,

253 2015). However, the functions of melatonin in spiders remain largely untested.

254 Earlier maturation has potential consequences for body size, as a shorter development time

255 affords less time to accumulate body mass. Here, 20 lux spiders were smaller at maturity, largely

256 due to their earlier maturation. However, when maturation time was statistically controlled 
257 spiders (particularly females) reared under light at night were also smaller than 0 lux spiders,

258 suggesting that ALAN may directly affect growth rate in this species. This contrasts with a

259 previous study in the cabbage moth which found no evidence that exposure to ALAN affected

260 rates of body mass growth (van Geffen et al., 2014), but such effects have received little

261 attention across other invertebrate taxa. The length of the intermoult period in spiders is largely

262 determined by rates of energy accumulation and increases in body mass (Nijhout, 2003). ALAN

263 may disrupt the body mass threshold for moulting and maturation to occur, resulting in lower

264 increases in body mass and therefore a smaller body size at maturation. Further, artificial light

265 potentially impaired their ability to consume food, or to convert food into body mass. Food

266 consumption was kept as similar as possible between the two treatment groups, so a

267 physiological disruption is the most likely explanation. The biological clocks that are regulated

268 by melatonin in turn modulate feeding behaviours through effects on hormones that regulate

269 hunger and satiety (Challet, 2015; Fonken \& Nelson, 2014). These systems can also affect the

270 physiological processing of food (Challet, 2015; Fonken \& Nelson, 2014; Fonken et al., 2010).

271 Hence, the impacts of ALAN on melatonin can cascade to fundamentally alter development and

272 growth. To our knowledge, the effects of ALAN on these hormones have not been explicitly

273 tested in arthropods, but analogues of some of these hormones have comparable physiological

274 roles in insects (Mataruga et al., 2009).

275 A major cost of exposure to ALAN is an increase in mortality (Eisenbeis \& Hassel, 2000;

276 Longcore \& Rich, 2004). Spiders exposed to ALAN exhibited higher lifetime mortality rates but,

277 as ALAN also stimulated earlier maturation, the number of spiders that reached maturity and

278 adult longevity were both comparable across the two groups. This increase in mortality may have

279 been driven by increased oxidative stress, as is suggested for other species (Jones et al., 2015). 
280 Alternatively, it may have resulted from their accelerated development, as resources were

281 diverted from growth and maintenance into reproductive development (Boggs, 1992). In contrast

282 to previous studies (McLay et al., 2017), there was no effect of ALAN on adult longevity. This

283 can be explained by a trade-off between the deleterious effects of aging and the benefits of

284 accruing more body reserves. Spiders in the 0 lux treatment aged more prior to maturing, so their

285 adult lifespan would be shortened; however, they also had greater body reserves, prolonging

286 their adult lifespan. The high mortality we observed in both treatment groups may have been a

287 result of the unnatural diet our spiders experienced, particularly as their diet lacked moths.

288 However, this unnatural diet affected both treatment groups equally, so it is unlikely that it

289 would dramatically alter our conclusions.

290 The impact of ALAN on the viability of urban spider populations depends on its effects on the

291 reproductive fitness of individual spiders in a population. The 20 lux spiders produced the same

292 number of eggsacs but considerably fewer spiderlings compared to 0 lux spiders. The reduction

293 in fecundity for 20 lux females was largely explained by ALAN induced differences in body

294 mass, as similarly sized females produced comparable numbers of eggs regardless of light

295 treatment. The lack of strong size-independent effects of ALAN on fecundity is contrary to

296 previous results in Drosophila (McLay et al., 2017). Nonetheless, our results suggest that a

297 smaller body size due to ALAN exposure will lead to a reduction in reproductive fitness. There

298 was no difference between treatment groups in adult longevity, so both groups had an equal

299 amount of time for egg production. However, under natural conditions, predation and declining

300 winter temperatures are major sources of mortality, so earlier maturation may extend the

301 breeding period (Dominoni et al., 2013; Schneider \& Elgar, 2002). Hence, the ALAN-induced 
302 trade-off between maturing earlier or maturing larger also implies a trade-off between a longer

303 breeding period or producing more spiderlings per eggsac for a shorter period.

304 In this study, we tested the effects of light treatment with both groups provided with the same

305 amount of food, whereas spiders that build their webs near lights are likely to receive

306 considerable foraging benefits (Adams, 2000; Catherine L. Craig, 1987). If greater food intake

307 increases reproductive output (Kreiter \& Wise, 2001; Reed et al., 2007), the foraging benefits

308 associated with artificial lights have the potential to at least partially compensate for the

309 reproductive costs of this trade-off (Lowe et al., 2014). This benefit may be tempered by

310 observations of LED lights failing to attract moths -25 webs over 3 nights failed to catch moths,

311 despite the observed presence of moths in the habitat (NJW, under review) - and decreasing

312 moth capture rates in other orb-weavers (Yuen \& Bonebrake, 2017). Hence, the potential for

313 foraging benefits to mask developmental costs depends on how ALAN affects the types of prey

314 available to insectivores foraging around lights. We found no effect of light treatment on the

315 mass of individual spiderlings. This has important potential fitness implications, as offspring size

316 is related to offspring performance, including starvation tolerance and the ability to capture prey

317 (Walker et al., 2003). However, intergenerational effects may not be evident without further

318 measurements of performance and development in subsequent generations.

\section{CONCLUSIONS}

320 The combined direct and indirect effects of ALAN on urban insect populations depends on how

321 shifts in life history patterns in these spiders affect predator-prey interactions for these affected

322 spiders. Increased mortality and smaller body size may reduce the predation impact spiders exert

323 on insect populations, counteracting increases in predation due to mutual attraction of both

324 predator and prey towards artificial lights. Artificial light at night is associated with high levels 
325 of urbanisation (Elvidge et al., 2001; Hansen et al., 2001; Longcore \& Rich, 2004; Ma et al.,

326 2012) and spiders living in urban habitats will experience not only the impacts of ALAN, but

327 other environmental perturbations due to urbanisation. Understanding the impacts of

328 urbanisation more generally for spider populations, and the likely consequences for insect

329 communities, will require a more integrated consideration of these factors. Future research into

330 the effects of ALAN on urban insectivores more generally should consider the impacts on both

331 foraging success and development in individuals, and how these impacts translate into

332 population-level effects.

\section{ACKNOWLEDGEMENTS}

334 We thank Mark Elgar for his insightful advice and manuscript comments. We thank Lucy

335 McLay, Caitlyn Perry and Po Peng for their help with spider maintenance, and Katrina-Lee Ware

336 for counting the majority of the spiderlings.

\section{REFERENCES}

338 Adams, M. R. (2000). Choosing hunting sites: Web site preferences of the orb weaver spider,

339 Neoscona crucifera, relative to light cues. Journal of Insect Behavior, 13(3), 299-305.

$340 \quad$ https://doi.org/10.1023/A:1007771332721

341 Adkisson, P. L. (1966). Internal Clocks and Insect Diapause. Science, 154(3746), 234-241.

342 https://doi.org/10.1126/science.154.3746.234

343 Bedrosian, T. a, Fonken, L. K., Walton, J. C., \& Nelson, R. J. (2011). Chronic exposure to dim

344 light at night suppresses immune responses in Siberian hamsters. Biology Letters, (January),

$345 \quad 468-471$. https://doi.org/10.1098/rsbl.2010.1108

346 Boggs, C. L. (1992). Resource Allocation: Exploring Connections between Foraging and Life 
Bolger, D. T., Beard, K. H., Suarez, A. V., \& Case, T. J. (2008). Increased abundance of native and non-native spiders with habitat fragmentation. Diversity and Distributions, 14(4), 655665. https://doi.org/10.1111/j.1472-4642.2008.00470.x

351 Bonaric, J. C. (1987). Moulting hormones. In W. Nentwig (Ed.), Ecophisiology of spiders (pp. 352 111-120). Berlin: Springer-Verlag.

353 Brown, K. M. (1981). Foraging ecology and niche partitioning in orb-weaving spiders.

354 Oecologia (Berlin), 50, 380-385. https://doi.org/10.1007/BF00344980

355 Brüning, A., Hölker, F., \& Wolter, C. (2011). Artificial light at night: Implications for early life 356 stages development in four temperate freshwater fish species. Aquatic Sciences, 73(1), 143357 152. https://doi.org/10.1007/s00027-010-0167-2

358 Challet, E. (2015). Keeping circadian time with hormones. Diabetes, Obesity and Metabolism, 359 17(S1), 76-83. https://doi.org/10.1111/dom.12516

360 Christie, F. J., Cassis, G., \& Hochuli, D. F. (2010). Urbanization affects the trophic structure of 361 arboreal arthropod communities. Urban Ecosystems, 13(2), 169-180.

362 https://doi.org/10.1007/s11252-009-0115-X

363 Craig, C. L. (1987). The ecological and evolutionary interdependence between web architecture 364 and web silk spun by orb web weaving spiders. Biological Journal of the Linnean Society, 365 30(2), 135-162. https://doi.org/10.1111/j.1095-8312.1987.tb00294.x

366 Craig, C. L., \& Bernard, G. D. (1990). Insect attraction to ultraviolet-reflecting spider webs and 367 web decorations. Ecology, 71(2), 616-623. https://doi.org/10.2307/1940315

368 Dahirel, M., Dierick, J., De Cock, M., \& Bonte, D. (2017). Intraspecific variation shapes 369 community-level behavioral responses to urbanization in spiders. Ecology, 98(9), 2379- 
2390. https://doi.org/10.1002/ecy.1915

371 Dominoni, D., Quetting, M., \& Partecke, J. (2013). Artificial light at night advances avian

372 reproductive physiology. Proceedings of the Royal Society B: Biological Sciences,

373 280(February), 20123017. https://doi.org/10.1098/rspb.2012.3017

374 Durrant, J., Botha, L. M., Green, M. P., \& Jones, T. M. (2018). Artificial light at night prolongs

375 juvenile development time in the black field cricket, Teleogryllus commodus. Journal of

376 Experimental Zoology Part B: Molecular and Developmental Evolution, 330, 225-233.

377 https://doi.org/10.1002/jez.b.22810

378 Durrant, J., Michaelides, E. B., Rupasinghe, T., Tull, D., Green, M. P., \& Jones, T. M. (2015).

379 Constant illumination reduces circulating melatonin and impairs immune function in the

380 cricket Teleogryllus commodus. PeerJ, 3, e1075. https://doi.org/10.7717/peerj.1075

381 Eisenbeis, G., \& Hänel, A. (2009). Light pollution and the impact of artificial night lighting on

382 insects. Ecology of Cities and Towns, Chapter 15(Sixma 2000), 243-263.

383 https://doi.org/http://dx.doi.org/10.1017/CBO9780511609763.016

384 Eisenbeis, G., \& Hassel, F. (2000). Attraction of nocturnal insects to street lights - a study of municipal lighting systems in a rural area of Rheinhessen (Germany). Natur Und Landschaft, 75(4), 145-156.

Elgar, M. A., \& Jones, T. M. (2008). Size-dependent mating strategies and the risk of cannibalism. Biological Journal of the Linnean Society, 94(2), 355-363. https://doi.org/10.1111/j.1095-8312.2008.00986.x

390 Elvidge, C. D., Imhoff, M. L., Baugh, K. E., Hobson, V. R., Nelson, I., Safran, J., ... Tuttle, B.

391 T. (2001). Night-time lights of the world: 1994-1995. ISPRS Journal of Photogrammetry 392 and Remote Sensing, 56(2), 81-99. https://doi.org/https://doi.org/10.1016/S0924- 
394 Firebaugh, A., \& Haynes, K. J. (2016). Experimental tests of light-pollution impacts on nocturnal 395 insect courtship and dispersal. Oecologia, 182(4), 1203-1211.

396 https://doi.org/10.1007/s00442-016-3723-1

397 Fonken, L. K., \& Nelson, R. J. (2014). The effects of light at night on circadian clocks and 398 metabolism. Endocrine Reviews, 35(4), 648-670. https://doi.org/10.1210/er.2013-1051

399 Fonken, L. K., Workman, J. L., Walton, J. C., Weil, Z. M., Morris, J. S., Haim, A., \& Nelson, R. 400 J. (2010). Light at night increases body mass by shifting the time of food intake.

401 Proceedings of the National Academy of Sciences, 107(43), 18664-18669.

402 Gaston, K. J., Bennie, J., Davies, T. W., \& Hopkins, J. (2013). The ecological impacts of 403 nighttime light pollution: A mechanistic appraisal. Biological Reviews, 88(4), 912-927. 404 https://doi.org/10.1111/brv.12036

405 Gaston, K. J., Davies, T. W., Bennie, J., \& Hopkins, J. (2012). Reducing the ecological 406 consequences of night-time light pollution: Options and developments. Journal of Applied $407 \quad$ Ecology, 49(6), 1256-1266. https://doi.org/10.1111/j.1365-2664.2012.02212.x

408 Girish, B. P., Swetha, C. H., \& Reddy, P. S. (2015). Induction of ecdysteroidogenesis, methyl 409 farnesoate synthesis and expression of ecdysteroid receptor and retinoid X receptor in the 410 hepatopancreas and ovary of the giant mud crab, Scylla serrata by melatonin. General and 411 Comparative Endocrinology, 217-218, 37-42. https://doi.org/10.1016/j.ygcen.2015.05.007

412 Hale, R., \& Swearer, S. E. (2016). Ecological traps: current evidence and future directions.

$413 \quad$ Proceedings of the Royal Society B: Biological Sciences, 283(1824), 20152647.

$414 \quad$ https://doi.org/10.1098/rspb.2015.2647

415 Hansen, J., Ruedy, R., Sato, M., Imhoff, M., Lawrence, W., Easterling, D., ... Karl, T. (2001). A 
416 closer look at United States and global surface temperature change. Journal of Geophysical

417 Research: Atmospheres, 106(D20), 23947-23963. https://doi.org/10.1029/2001JD000354

418 Heiling, A. M. (1999). Why do nocturnal orb-web spiders (Araneidae) search for light?

419 Behavioral Ecology and Sociobiology, 46(1), 43-49.

$420 \quad$ https://doi.org/10.1007/s002650050590

421 Heiling, A. M., \& Herberstein, M. E. (1999). The Importance of Being Larger: Intraspecific

422 Competition for Prime Web Sites in Orb-Web Spiders (Araneae, Araneidae). Behaviour,

423 136(5), 669-677. https://doi.org/10.1163/156853999501513

424 Heiling, A. M., \& Herberstein, M. E. (2004). Predator-prey coevolution: Australian native bees avoid their spider predators. Source: Proceedings: Biological Sciences, 271(4), 196-198. https://doi.org/10.1098/rsbl.2003.0138

427 Henneken, J., Jones, T. M., Goodger, J. Q. D., Dias, D. A., Walter, A., \& Elgar, M. A. (2015). 428 Diet influences female signal reliability for male mate choice. Animal Behaviour, 108, 215429 221. https://doi.org/10.1016/j.anbehav.2015.07.023

430 Herberstein, M. E., \& Elgar, M. A. (1994). Foraging strategies of Eriophora transmarina and 431 Nephila plumipes (Araneae: Araneoidea): Nocturnal and diurnal orb-weaving spiders. Australian Journal of Ecology, 19(4), 451-457. https://doi.org/10.1111/j.1442-

434 Honěk, A. (1993). Intraspecific Variation in Body Size and Fecundity in Insects: A General 435 Relationship. Oikos, 66(3), 483. https://doi.org/10.2307/3544943

436 Jones, M., Durrant, J., Michaelides, E. B., \& Green, M. P. (2015). Melatonin : a possible link 437 between the presence of artificial light at night and reductions in biological fitness.

438 Philosophical Transactions of the Royal Society of London. Series B, Biological Sciences, 
440 Kinzig, A. P., Warren, P., Martin, C., Hope, D., \& Katti, M. (2005). The effects of human 441 socioeconomic status and cultural characteristics on urban patterns of biodiversity. Ecology 442 and Society, 10(1), NIL_181-NIL_193. https://doi.org/10.5751/ES-01264-100123

443 Kreiter, N. A., \& Wise, D. H. (2001). Prey availability limits fecundity and influences the 444 movement pattern of female fishing spiders. Oecologia, 127(3), 417-424.

$445 \quad$ https://doi.org/10.1007/s004420000607

446

447

448

449

Lacoeuilhe, A., Machon, N., Julien, J. F., Le Bocq, A., \& Kerbiriou, C. (2014). The influence of low intensities of light pollution on bat communities in a semi-natural context. PLoS ONE, 9(10). https://doi.org/10.1371/journal.pone.0103042

Longcore, T., \& Rich, C. (2004). Ecological Light Pollution - Review. Ecological Society of America, 2(4), 191-198. https://doi.org/10.1890/1540-9295(2004)002[0191:ELP]2.0.CO;2

Lowe, E. C., Wilder, S. M., \& Hochuli, D. F. (2014). Urbanisation at multiple scales is associated with larger size and higher fecundity of an orb-weaving spider. PLoS ONE, 9(8). https://doi.org/10.1371/journal.pone.0105480

Ma, T., Zhou, C., Pei, T., Haynie, S., \& Fan, J. (2012). Quantitative estimation of urbanization dynamics using time series of DMSP/OLS nighttime light data: A comparative case study from China's cities. Remote Sensing of Environment, 124, 99-107. https://doi.org/10.1016/j.rse.2012.04.018

Mayntz, D., Toft, S., \& Vollrath, F. (2003). Effects of prey quality and availability on the life history of a trap-building predator. Oikos, 101(3), 631-638. https://doi.org/10.2307/3547791

McLay, L. K., Green, M. P., \& Jones, T. M. (2017). Chronic exposure to dim artificial light at 
night decreases fecundity and adult survival in Drosophila melanogaster. Journal of Insect Physiology, 100(May), 15-20. https://doi.org/10.1016/j.jinsphys.2017.04.009

464

465

466

467

468

469

470

471

472

473

474

475

476

477

478

479

480

481

482

483

484

Minnaar, C., Boyles, J. G., Minnaar, I. A., Sole, C. L., \& McKechnie, A. E. (2015). Stacking the odds: Light pollution may shift the balance in an ancient predator-prey arms race. Journal of Applied Ecology, 52(2), 522-531. https://doi.org/10.1111/1365-2664.12381

Miyashita, K. (1987). Development and egg sac production of Achaearanea tepidariorum (CL Koch)(Araneae, Theridiidae) under long and short photoperiods. Journal of Arachnology, 51-58. https://doi.org/10.2307/3705508

Murakami, Y. (1983). Factors determining the prey size of the orb-web spider, Argiope amoena (L. Koch) (Argiopidae). Oecologia, 57(October 1978), 72-77.

Navara, K. J., \& Nelson, R. J. (2007). The dark side of light at night: Physiological, epidemiological, and ecological consequences. Journal of Pineal Research, 43(3), 215-224. https://doi.org/10.1111/j.1600-079X.2007.00473.x

Nelson, R. J., Denlinger, D. L., \& Somers, D. E. (Eds.). (2010). Photoperiodism: the biological calendar (Jan 27). Oxford University Press.

Nijhout, H. F. (2003). The control of body size in insects. Developmental Biology, 261(1), 1-9. https://doi.org/10.1016/S0012-1606(03)00276-8

Nylin, S., \& Gotthard, K. (1998). Plasticity in Life-History Traits. Annual Review of Entomology, 43(125), 63-83. https://doi.org/10.1146/annurev.ento.43.1.63

Perić - Mataruga, V., Mirčić, D., Vlahović, M., Mrdaković, M., Todorović, D., Stevanović, D., \& Milošević, V. (2009). Effects of ghrelin on the feeding behavior of Lymantria dispar L. (Lymantriidae) caterpillars. Appetite, 53(1), 147-150. https://doi.org/10.1016/j.appet.2009.05.009 
485 R Core Team. (2017). R: A language and environment for statistical computing. Vienna, Austria:

486 R Foundation for Statistical Computing. Retrieved from http://www.r-project.org/.

487 Reed, D. H., Nicholas, A. C., \& Stratton, G. E. (2007). Inbreeding levels and prey abundance

488 interact to determine fecundity in natural populations of two species of wolf spider.

489 Conservation Genetics, 8(5), 1061-1071. https://doi.org/10.1007/s10592-006-9260-4

490 Rydell, J. (1992). Exploitation of Insects around Streetlamps by Bats in Sweden. Functional

$491 \quad$ Ecology, 6(6), 744-750. https://doi.org/10.2307/2389972

492 Schaefer, M. (1987). Life cycles and diapause. In W. Nentwig (Ed.), Ecophysiology of Spiders

493 (pp. 331-347). Springer-Verlag.

494 Schneider, J. M., \& Elgar, M. A. (2002). Sexual cannibalism in Nephila plumipes as a

495 consequence of female life history strategies. Journal of Evolutionary Biology, 15(1), 84-

496 91. https://doi.org/10.1046/j.1420-9101.2002.00363.x

497 Shah, M., Suzuki, T., Ghazy, N. A., Amano, H., \& Ohyama, K. (2011). Night-interrupting light

498 inhibits diapause induction in the Kanzawa spider mite, Tetranychus kanzawai Kishida

499 (Acari: Tetranychidae). Journal of Insect Physiology, 57(9), 1185-1189.

$500 \quad$ https://doi.org/10.1016/j.jinsphys.2011.05.018

501 Shochat, E., Stefanov, W. L., Whitehouse, M. E. A., \& Faeth, S. H. (2004). Urbanization and

502 spider diversity: influences of human modification of habitat structure and productivity.

503 Ecological Applications, 14(1), 268-280. https://doi.org/10.1890/02-5341

504 Tauber, M. J., Tauber, C. A., \& Masaki, S. (Eds.). (1986). Seasonal Adaptations of Insects.

505 Oxford University Press.

506 Therneau, T. (2015). A Package for Survival Analysis in S. Retrieved from http://cran.r-

507 project.org/package $=$ survival 
508 Trubl, P., Gburek, T., Miles, L., \& Johnson, J. C. (2012). Black widow spiders in an urban 509 desert: Population variation in an arthropod pest across metropolitan Phoenix, AZ. Urban 510 Ecosystems, 15(3), 599-609. https://doi.org/10.1007/s11252-011-0223-2

511 van Geffen, K. G., van Eck, E., de Boer, R. A., van Grunsven, R. H. A., Salis, L., Berendse, F., 512 \& Veenendaal, E. M. (2015). Artificial light at night inhibits mating in a Geometrid moth. 513 Insect Conservation and Diversity, 8(3), 282-287. https://doi.org/10.1111/icad.12116

514 van Geffen, K. G., van Grunsven, R. H. A., van Ruijven, J., Berendse, F., \& Veenendaal, E. M.

515 (2014). Artificial light at night causes diapause inhibition and sex-specific life history

516 changes in a moth. Ecology and Evolution, 4(11), 2082-2089.

517 https://doi.org/10.1002/ece3.1090

518 van Langevelde, F., Ettema, J. A., Donners, M., WallisDeVries, M. F., \& Groenendijk, D.

519 (2011). Effect of spectral composition of artificial light on the attraction of moths.

520 Biological Conservation, 144(9), 2274-2281. https://doi.org/10.1016/j.biocon.2011.06.004

521 Vivien-Roels, B., \& Pévet, P. (1993). Melatonin: presence and formation in invertebrates.

522 Experientia, 49(8), 642-647. https://doi.org/10.1007/BF01923945

523 Vollrath, F. (1987). Growth, Foraging, and Reproductive Success. In W. Nentwig (Ed.), 524 Ecophysiology of Spiders (pp. 357-379). Berlin: Springer-Verlag.

525 Walker, S. E., Rypstra, A. L., \& Marshall, S. D. (2003). The relationship between offspring size 526 and performance in the wolf spider. Evolutionary Ecology, 19-28.

527 Yuen, S. W., \& Bonebrake, T. C. (2017). Artificial night light alters nocturnal prey interception 528 outcomes for morphologically variable spiders. PeerJ, 5, e4070. 


\section{Table $\mathbf{1}$ (on next page)}

Effects of light treatment on development time and total growth

Measures (mean $\pm \mathrm{SE}$ ) of development time and total growth at maturity for males and females in the two lighting treatment groups - dark at night (0 lux) and light at night (20 lux), and the full models for these effects. Non-significant $(P>0.1)$ interactions were dropped from models. Superscript letters above means and standard errors denote significant differences $(P<0.05)$ in treatment-specific or sex-specific comparisons. 


\begin{tabular}{|c|c|c|c|c|c|c|}
\hline \multirow{2}{*}{ Models } & \multicolumn{2}{|c|}{ O lux at Night } & \multicolumn{2}{|c|}{20 lux at Night } & \multirow{2}{*}{ Statistic } & \multirow{2}{*}{ P-value } \\
\hline & Males & Females & Males & Females & & \\
\hline \multicolumn{7}{|l|}{ a) Age at Maturation (days) } \\
\hline Light Treatment & $300.28 \pm 6.22$ & $334.91 \pm 7.12$ & $262.03 \pm 6.11$ & $272.35 \pm 5.38$ & $\mathrm{~F}_{(1,131)}=85.78$ & $<0.0001$ \\
\hline Sex & & & & & $\mathrm{F}_{(1,131)}=16.97$ & $<0.0001$ \\
\hline \multicolumn{7}{|l|}{ b) Number of Juvenile Moults } \\
\hline Light Treatment & $11.61 \pm 0.30$ & $12.90 \pm 0.36$ & $10.33 \pm 0.29$ & $11.17 \pm 0.34$ & $\mathrm{~F}_{(1,131)}=25.28$ & $<0.0001$ \\
\hline Sex & & & & & $\mathrm{F}_{(1,131)}=10.99$ & 0.001 \\
\hline \multicolumn{7}{|c|}{ c) Length of Intermoult Period (days) } \\
\hline Light Treatment & $31.30 \pm 1.17$ & $30.42 \pm 0.80$ & $33.05 \pm 1.62$ & $28.01 \pm 1.01$ & $\mathrm{~F}_{(1,131)}=0.02$ & 0.89 \\
\hline Sex & & & & & $\mathrm{F}_{(1,131)}=4.91$ & 0.03 \\
\hline \multicolumn{7}{|l|}{ d) Body Mass (mg) } \\
\hline Light Treatment & $290.1 \pm 14.44^{\mathrm{A}}$ & $456.07 \pm 19.78^{\mathrm{B}}$ & $126.47 \pm 8.70^{\mathrm{C}}$ & $162.56 \pm 7.99^{\mathrm{D}}$ & $\mathrm{F}_{(1,131)}=247.6$ & $<0.0001$ \\
\hline Sex & & & & & $\mathrm{F}_{(1,131)}=57.15$ & $<0.0001$ \\
\hline Light Treatment $\times$ Sex & & & & & $\mathrm{F}_{(1,131)}=23.32$ & $<0.0001$ \\
\hline \multicolumn{7}{|l|}{ e) Tibia Length (mm) } \\
\hline Light Treatment & $6.98 \pm 0.14^{\mathrm{A}}$ & $6.81 \pm 0.11^{\mathrm{A}}$ & $5.43 \pm 0.11^{\mathrm{B}}$ & $4.78 \pm 0.10^{\mathrm{C}}$ & $\mathrm{F}_{(1,131)}=163.16$ & $<0.0001$ \\
\hline Sex & & & & & $\mathrm{F}_{(1,131)}=0.52$ & 0.47 \\
\hline Light Treatment $\times$ Sex & & & & & $\mathrm{F}_{(1,131)}=10.71$ & 0.001 \\
\hline
\end{tabular}




\section{Table 2 (on next page)}

Effects of light treatment on fecundity and offspring size

Measures (mean $\pm \mathrm{SE}$ ) of fecundity and offspring size for spiders in the dark at night (0 lux) and light at night (20 lux) treatments. 


\begin{tabular}{|l|c|c|c|}
\hline Models & 0 lux at Night & 20 lux at Night & Statistic \\
\hline a) Eggsacs per Female (count) & & & \\
\hline Light Treatment & $5.18 \pm 0.47$ & $5.40 \pm 0.46$ & $\chi^{2}=0.11, d f=1$ \\
\hline b) Spiderlings per Female (count) & & & 0.74 \\
\hline Light Treatment & $4367.92 \pm 361.61$ & $1471.27 \pm 234.37$ & $\chi^{2}=43.06, d f=1$ \\
\hline c) Spiderlings per Eggsac (count) & & & $<\mathbf{0 . 0 0 0 1}$ \\
\hline Light Treatment & $895.07 \pm 35.01$ & $311.23 \pm 22.33$ & $\chi^{2}=183.34, d f=1$ \\
\hline d) Individual Spiderling Mass (mg) & & & $<\mathbf{0 . 0 0 0 1}$ \\
\hline Light Treatment & $2.36 \pm 0.05$ & $2.33 \pm 0.05$ & $\mathrm{~F}_{(1,45)}=0.16$ \\
\hline
\end{tabular}




\section{Figure 1}

Relationship between number of moults and age at which spiders reached final moult

The relationship between the number of recorded moults and age (in days) at which male and female spiders reared in the dark at night ( 0 lux) and light at night (20 lux) treatments completed their final moult. The black line represents the fitted regression line $(y=0.03 x+$ 3.13; $R_{m}{ }_{m}=0.48, R_{c}{ }_{c}=0.61$ ) for the overall relationship between number of moults and age at maturation.

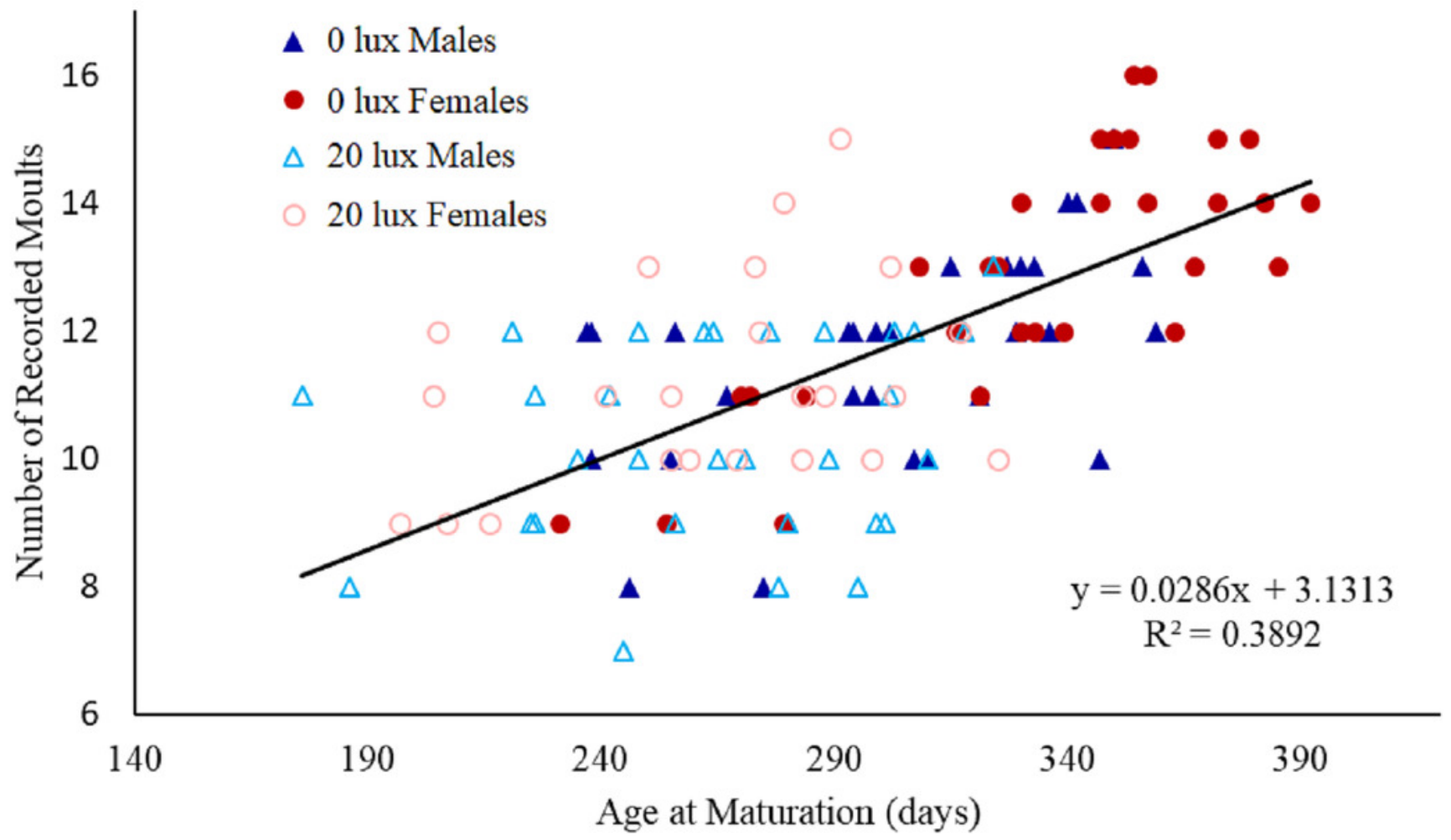


Figure 2

Effect of light treatment on survival over the entire lifespan

Survivorship curve for dark at night ( 0 lux) and light at night (20 lux) treatment group spiders over their entire lifespan. Day 0 represents $14.95 \pm 1.47$ (mean $\pm \mathrm{SE}$ ) days since hatching, at which point spiderlings were placed individually into cups and subjected to their lighting conditions. Prior to this point, all spiderlings experienced dark at night conditions. Shaded areas represent $95 \%$ confidence intervals from a Kaplan-Meier survival analysis.

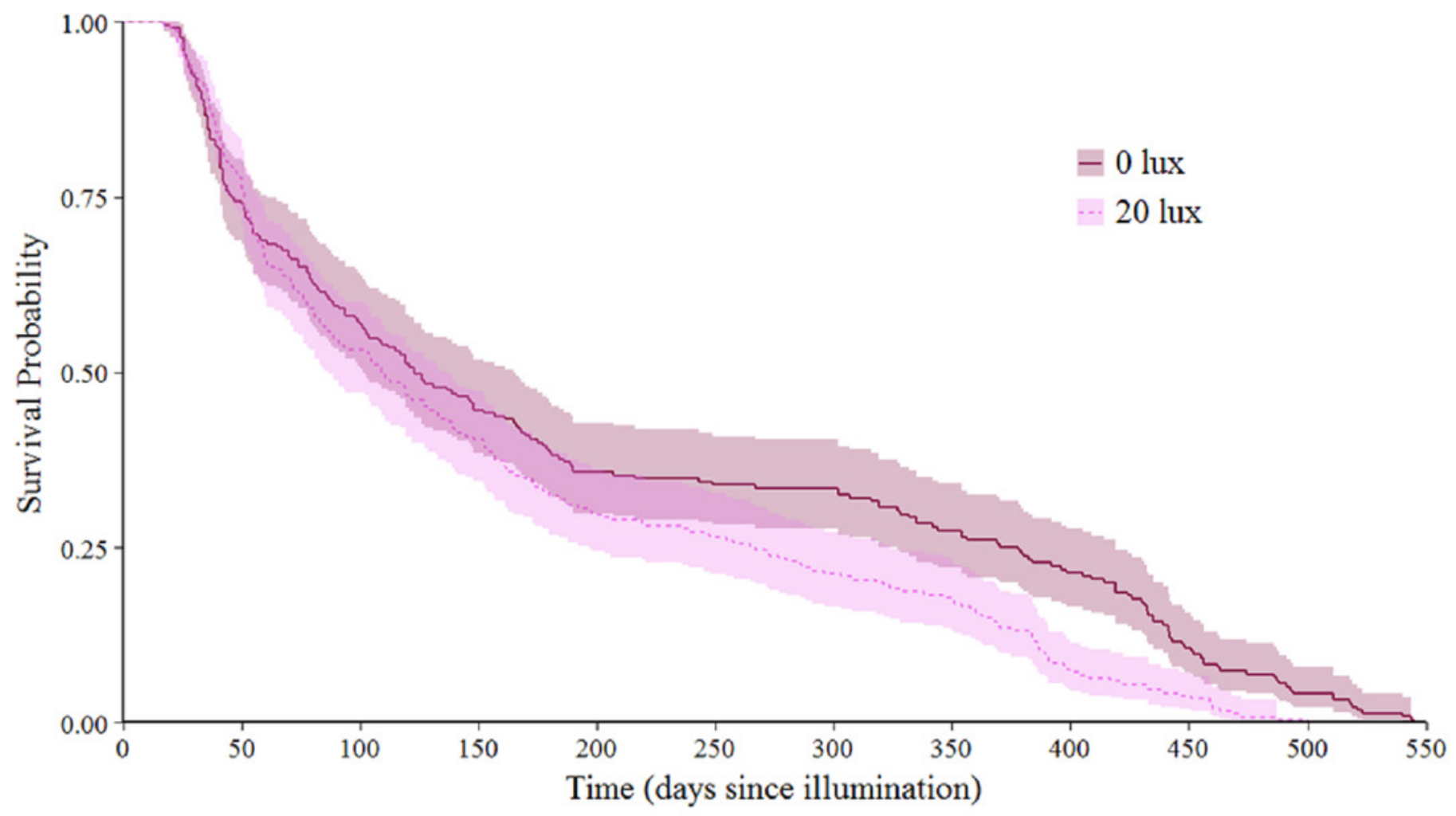




\section{Figure 3}

Effect of light treatment on adult survival

Adult longevity (survival probabilities as adults) curves for dark at night ( 0 lux) and light at night (20 lux) treatment males and females. Day 0 represents the day at which each spider matured. Shaded areas represent $95 \%$ confidence intervals from a Kaplan-Meier survival analysis.

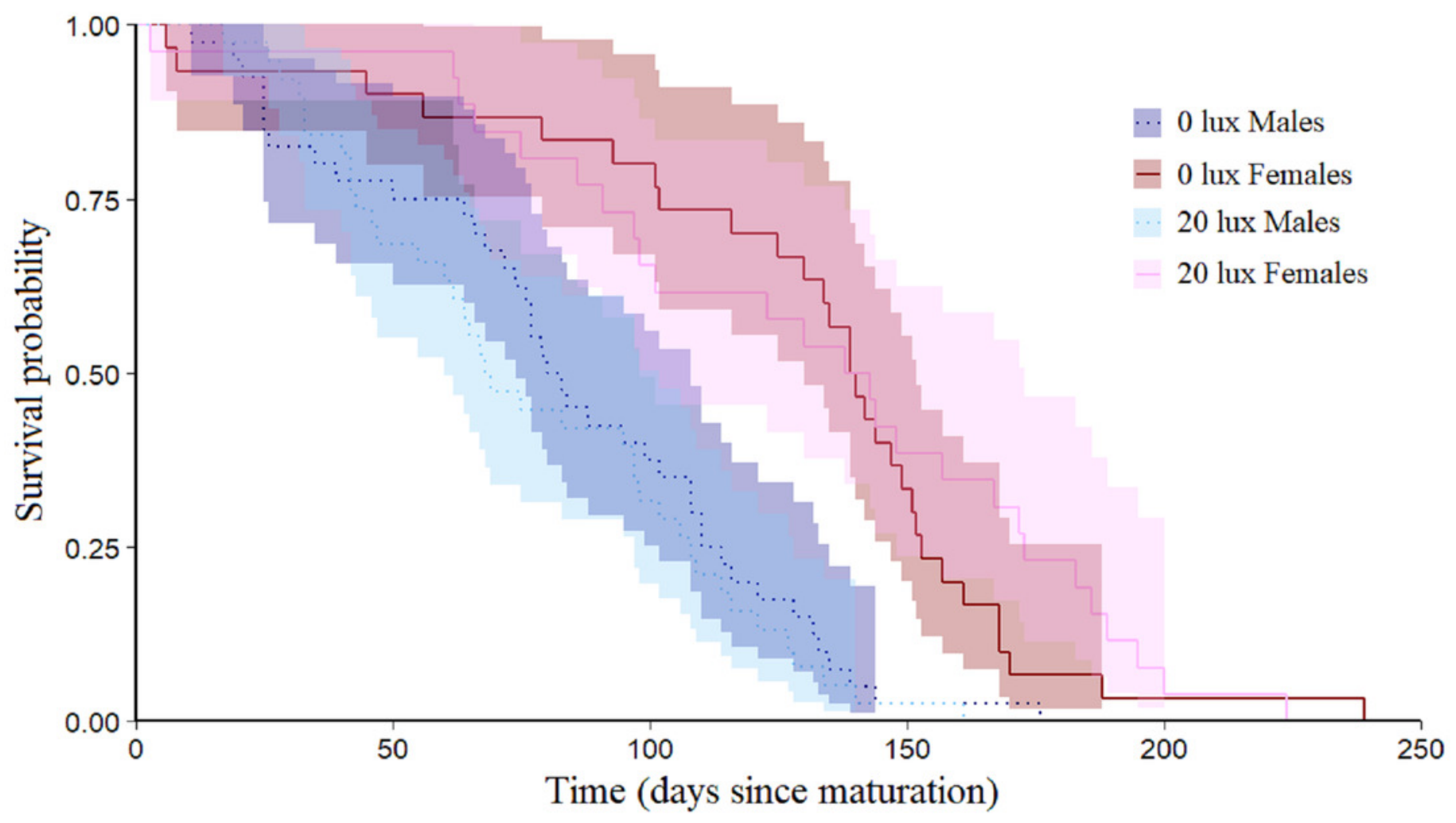


Figure 4

Effect of light treatment and sex on the relationship between body mass and age at maturity

The relationship between body mass $(\mathrm{mg}$ ) at maturity (after final moult and before feeding again) and age (in days) at which male and female spiders reared in the dark at night (0 lux) and light at night (20 lux) treatments completed their final moults. The black line represents the fitted regression line $\left(y=2.76 x-560.33 ; \mathrm{R}_{\mathrm{m}}{ }^{2}=0.61, \mathrm{R}_{\mathrm{c}}{ }_{\mathrm{c}}=0.75\right)$ for the overall relationship between body mass and age at maturation.

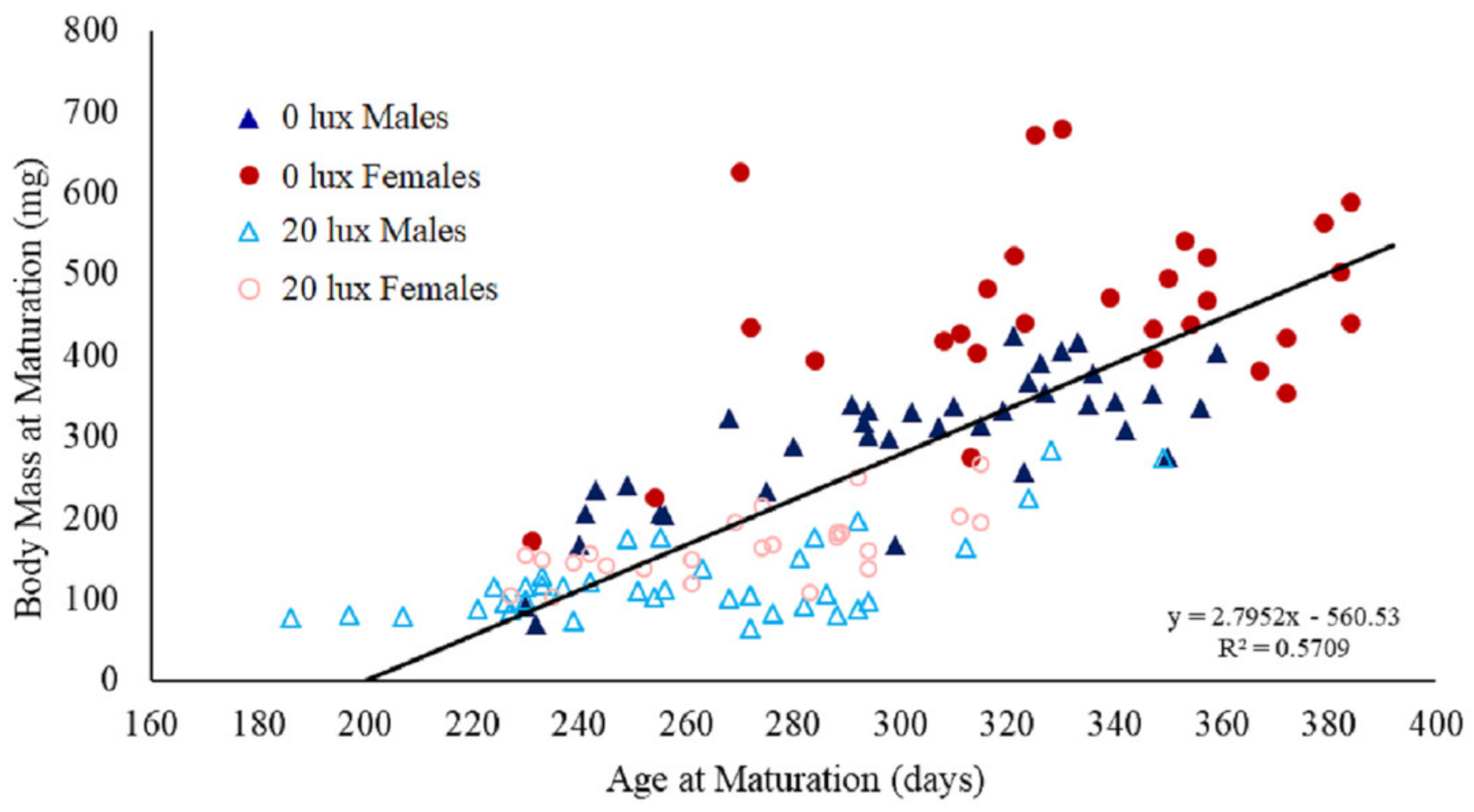


Figure 5

Effect of light treatment and sex on the relationship between tibial length and age at maturity

The relationship between tibial length $(\mathrm{mm})$ at maturity and age (in days) at which male and female spiders reared in the dark at night (0 lux) and light at night (20 lux) treatments completed their final moults. The black line represents the fitted regression line $(y=0.02 x+$ $0.63 ; R_{m}^{2}=0.49, R_{c}^{2}=0.65$ ) for the overall relationship between tibial length and age at maturation.

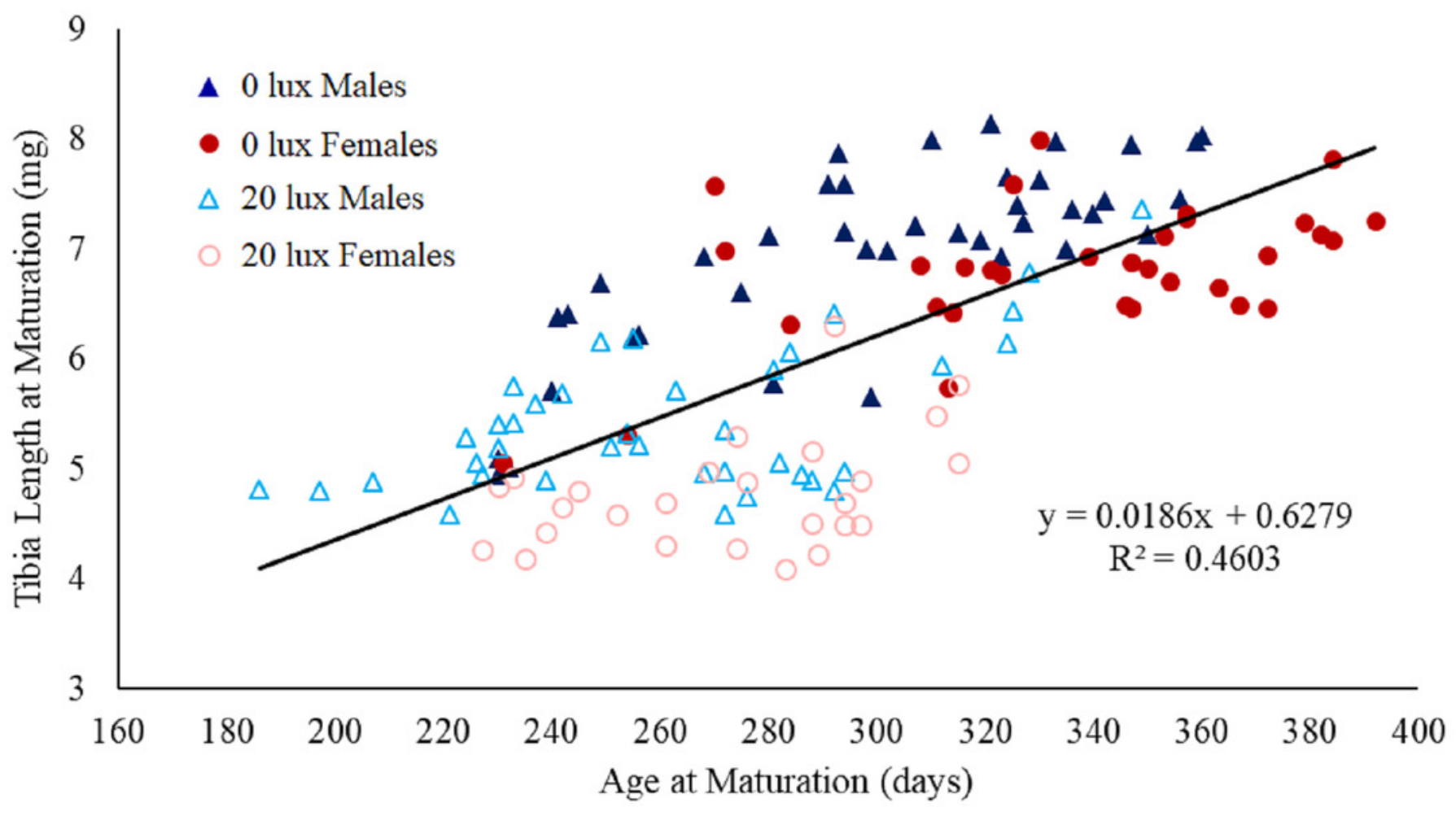




\section{Figure 6}

Effect of light treatment on the number of offspring produced by females

The relationship between the number of spiderlings per eggsac and the eggsac number for females in the dark at night (0 lux) and light at night (20 lux) treatments. Shaded areas represent $95 \%$ confidence bands.

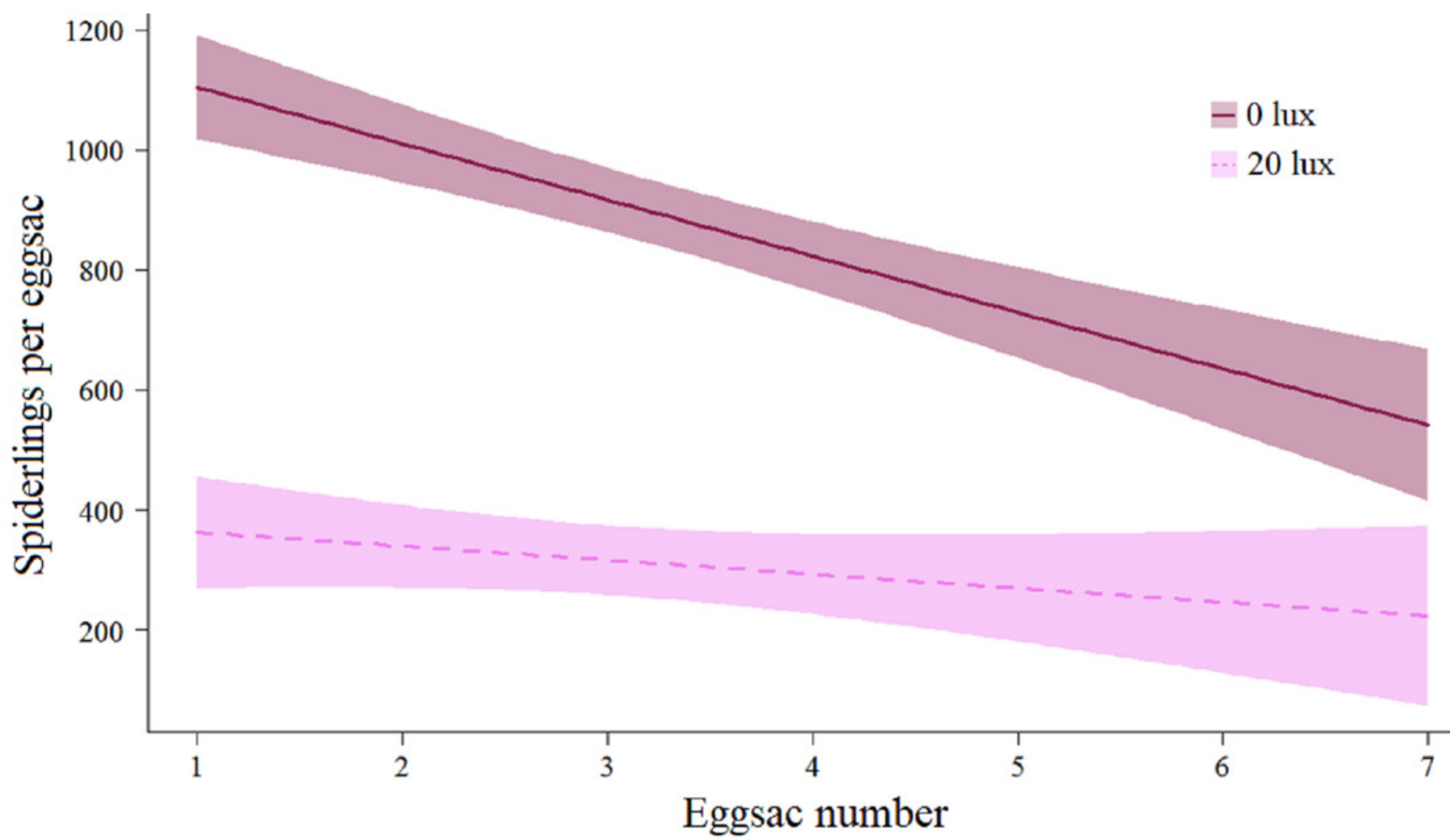

